CLINICAL STUDY

\title{
Testicular adrenal rests: evidence for luteinizing hormone receptors and for distinct types of testicular nodules differing for their autonomization
}

\author{
Salvatore Benvenga ${ }^{1}$, Giovanni Smedile ${ }^{2}$, Francesco Lo Giudice ${ }^{1}$, Francesco Trimarchi ${ }^{1}$ \\ ${ }^{1}$ Cattedra di Endocrinologia, University of Messina School of Medicine, 98125 Messina, Italy and ${ }^{2}$ Divisione di Endocrinologia, Azienda Ospedale \\ Piemonte, 98124 Messina, Italy \\ (Correspondence should be addressed to S Benvenga, Cattedra di Endocrinologia, Policlinico Universitario di Messina, Padiglione H, $4^{\circ}$ piano, 98125 , \\ Messina, Italy; E-mail: trimarcf@unime.it)
}

\begin{abstract}
We report one patient with 21-hydroxylase deficiency and associated bilateral macro-orchidism caused by nodular hyperplasia of testicular adrenal rests (TAR). The boy, referred to us when 10 years old, was born with bilateral cryptorchidism that was treated unsuccessfully with i.m. injections of human chorionic gonadotropin (hCG) and later on with orchidopexy. He was treated with oral dexamethasone (0.625 mg per day) for the following 13 years.

After one year, there was a marked reduction in steroid hormone levels (17-hydroxyprogesterone (17-OH P) from 27.2 to $1.2 \mathrm{nmol} / \mathrm{l}$, testosterone from $>104$ to $4.8 \mathrm{nmol} / \mathrm{l}$, estradiol $\left(\mathrm{E}_{2}\right)$ from 481 to $33 \mathrm{pmol} / \mathrm{l})$. After the same period of time, both testicular volume and nodularity decreased: from 45 to $18 \mathrm{ml}$ and from numerous to four nodules in the right testis, and from 40 to $13 \mathrm{ml}$ and from numerous to three nodules in the left testis. At the third year, there were transient increases in serum gonadotropins, testicular volume (right testis $=25 \mathrm{ml}$, left testis $=20 \mathrm{ml}$ ) and steroid hormones, including cortisol (serum ACTH and dehydroepiandrosterone sulfate remained suppressed). At the fourth year of follow-up, there were still four nodules in the right testis and three in the left testis. The LH-dependency (which implies possession of LH/hCG receptors) of these nodules was also substantiated by their steroidogenic response to an acute i.m. hCG test. An exogenous ACTH stimulation test increased serum 17-OH P and cortisol. Since these nodules, unlike the majority of those present initially, were not suppressed by the corticosteroid therapy and since they were not detected when the patient returned for control at 23 years of age, they had partial autonomy from ACTH. At 23 years of age, the patient had a single nodule in the right testis (right testis volume $=13 \mathrm{ml}$, left testis volume $=10 \mathrm{ml}$ ), which should have accounted for the consistent difference in size between the two gonads. Serum LH was about $7 \mathrm{mU} / \mathrm{l}$ and FSH about $23 \mathrm{mU} / \mathrm{l}$. The responsiveness of plasma steroid hormones to hCG had changed quantitatively and qualitatively. Secretion of cortisol was absent, secretion of 17-OH P and testosterone was reduced, and secretion of $\mathrm{E}_{2}$ was much increased. The ACTH stimulation test showed that serum cortisol did not respond, while the other steroids responded in the order of $17-\mathrm{OH} \mathrm{P}>\mathrm{E}_{2}>$ testosterone.

We conclude that there were three different groups of TAR when the patient was already 10 years old: (i) ACTH-sensitive (the majority), (ii) partially ACTH-insensitive but LH/hCG-sensitive (three nodules in the left testis and three in the right testis), (iii) almost entirely ACTH-insensitive and partially hCG-insensitive (a single nodule in the right testis). Probably, the never suppressed gonadotropin levels (presumably due to the bilateral testicular damage subsequent to the cryptorchid state) and the hCG therapy were major etiological factors for the appearance of the second and third population of TAR.
\end{abstract}

European Journal of Endocrinology 141 231-237

\section{Introduction}

Bilateral testicular adrenal rests (TAR) in patients with congenital or late-onset congenital adrenal hyperplasia (CAH or LOCAH) are relatively common, but true testicular tumors arising from TAR are rare (1). Macro-orchidism occurs because TAR share the adrenocorticotropin (ACTH)-driven hyperplasia with the adrenal glands. Typically, TAR-associated macroorchidism has been reported in patients with poor therapeutic control of the salt-losing form of CAH (1). TAR have also been reported sporadically in situations of high circulating ACTH other than CAH, e.g. Nelson's syndrome (2) and Cushing's disease (3). In addition to 
being ACTH-dependent, TAR secrete 17-hydroxyprogesterone (17-OH P) and cortisol (1). The precise origin of TAR is controversial (4). The hypotheses include derivation from adrenocortical cells or from peculiar ACTH-dependent Leydig cells or from undifferentiated stromal cells with the potential of differentiation into either adrenal-like cells or Leydig-like cells depending upon the stimulating tropin (4). Histologically, TAR are indistinguishable from Leydig cell tumors. They consist of polyhedric eosinophilic cells resembling Leydig cells except for the larger size and the absence of Reinke crystalloids (1, 5). Clearly, the adrenal-like nodules of the testes can be mistaken for testicular neoplasms; because of the said resemblance to Leydig cell tumors, an unnecessary orchidectomy may follow.

We report a patient, born with bilateral cryptorchidism, in whom the isosexual precocious pseudopuberty and bilateral macro-orchidism due to homozygous, non salt-losing form of 21-hydroxylase (21-OHase) deficiency progressed until our observation. Our case is of interest because TAR had the unusual property to oversecrete estradiol $\left(\mathrm{E}_{2}\right)$, were both ACTH-responsive as well as luteinizing hormone/human chorionic gonadotropin ( $\mathrm{LH} / \mathrm{hCG}$ )-responsive (i.e. they had both $\mathrm{ACTH}$ and $\mathrm{LH} / \mathrm{hCG}$ receptors) and were heterogeneous in terms of such responsiveness. We are aware of no similar case reported thus far.

\section{Case report}

GM was born in September 1972, from nonconsanguineous parents in a country town of the province of Messina. One brother had died three weeks after birth of 'shock'. GM was born with bilateral cryptorchidism; at the age of one year he was treated with hCG (Profasi, Serono (Rome, Italy), 500 IU i.m. per week for 6 weeks), but unsuccessfully. At 21 months his parents started noticing enlargement of the penis and appearance of pubic hair. Bilateral orchidopexy was performed when the child was three years old. The histology revealed small sheets of cells larger than Leydig cells that replaced the seminiferous tubules; collagenous fibers were also present.

A few months after orchidopexy, the full picture of iso-sexual precocious pseudopuberty (statural growth, appearance of the beard and axillary hair, muscular hypertropy, erotic fantasies, aggressiveness, deepening of the voice) developed and progressed aggressively. He was not evaluated (and therefore was untreated) until September 1982 when, at the age of 10 years, he was referred to one of us (GS) for 'suspicious bilateral testicular neoplasia in a boy with previous bilateral cryptorchidism', because cryptorchidism is 12-40 times more common in undescended testes than in scrotal ones (6). The physical appearance was that known as 'little Hercules'. His height and weight

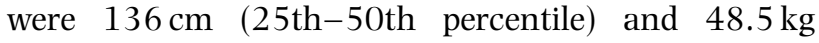
( $>97$ th percentile). Pubertal stage was T5. Testes were increased in size (right testis $45 \mathrm{ml}$; left testis $40 \mathrm{ml}$ ), both had an irregular surface because of numerous craggy, hard nodular masses. The histology showed small and large sheets of round and polygonal cells which were larger than typical Leydig cells. Reinke crystalloids were absent. The cytoplasm of these cells was pale and vacuolate; nuclei were vesicular and round or oval.

The prostate was of adult size, by manual palpation. Gynecomastia was absent. Bone age was advanced (16 years). Semen analysis (volume of the ejaculate $=1 \mathrm{ml}$ ) revealed azoospermia. The laboratory data are presented in the Results (Table 1 and Fig. 1). Based on the elevated basal and exogenous ACTH-elicited serum 17-OH P levels coexisting with low morning cortisol and high endogenous ACTH (Table 1), the diagnosis of

Table 1 Plasma hormone levels at the initial evaluation of the patient.

\begin{tabular}{|c|c|c|c|c|}
\hline \multirow[b]{2}{*}{ Hormones } & \multirow[b]{2}{*}{ Normal range* } & \multirow[b]{2}{*}{ Baseline } & \multicolumn{2}{|c|}{ After dexamethasone } \\
\hline & & & $1 \mathrm{mg}$ overnight & $2 \mathrm{mg} /$ day for 6 days \\
\hline $\begin{array}{l}\text { 17-OH P (nmol/l) } \\
\text { Peak, ACTH test }\end{array}$ & $\begin{array}{l}0.60-6.0 \\
<30\end{array}$ & $\begin{array}{l}27.2 \\
>150\end{array}$ & 11.5 & 5.4 \\
\hline $\begin{array}{l}\text { Cortisol }(\mathrm{nmol} / \mathrm{l}) \\
\Delta, \mathrm{ACTH} \text { test }\end{array}$ & $\begin{array}{l}248.4-634.8 \\
>276.0\end{array}$ & $\begin{array}{l}60.7 \\
27.6\end{array}$ & 38.6 & 24.8 \\
\hline DHEAS $(\mu \mathrm{mol} / \mathrm{l})$ & $3.2-8.2$ & 8.1 & 4.3 & 1.2 \\
\hline Aldosterone $(\mathrm{pmol} / \mathrm{l})$ & $55.4-609.4$ & 277 & 230 & 108 \\
\hline Testosterone (nmol/l) & $9.7-28.4$ & $>104.1$ & 46.8 & 13.2 \\
\hline Estradiol $(\mathrm{pmol} / \mathrm{l})$ & $36.7-128.4$ & 481 & 124.8 & 88.1 \\
\hline ACTH (pmol/l) & $4.4-17.6$ & 73.4 & 54.1 & 17.2 \\
\hline $\mathrm{FSH}(\mathrm{mU} / \mathrm{l})$ & $4.5-20$ & 8.6 & & \\
\hline$\Delta$, LHRH test & $>2$-fold increase & 1.0-fold & & \\
\hline $\mathrm{LH}(\mathrm{mU} / \mathrm{l})$ & $7-15$ & 9.1 & & \\
\hline$\Delta$, LHRH test & $>4$-fold increase & 1.1-fold & & \\
\hline
\end{tabular}

* Ranges given are for pubertal boys.

ACTH or LHRH i.v. tests were performed with $250 \mu \mathrm{g}$ or $100 \mu \mathrm{g}$ of the respective synthetic peptide. 
Figure 1 Changes in the profile of plasma gonadotropins and steroid hormones, and in testicular volume over the first 4 years of follow-up. Note how the corticosteroidinduced dramatic decline in sexual steroid levels (and testicular volume) was accompanied, during the first year, by the progressive increase in FSH and LH levels.

Gonadotropins peaked at the 3rd year and declined at the 4th year. Parallel changes in steroid hormone levels and testicular volume are striking.
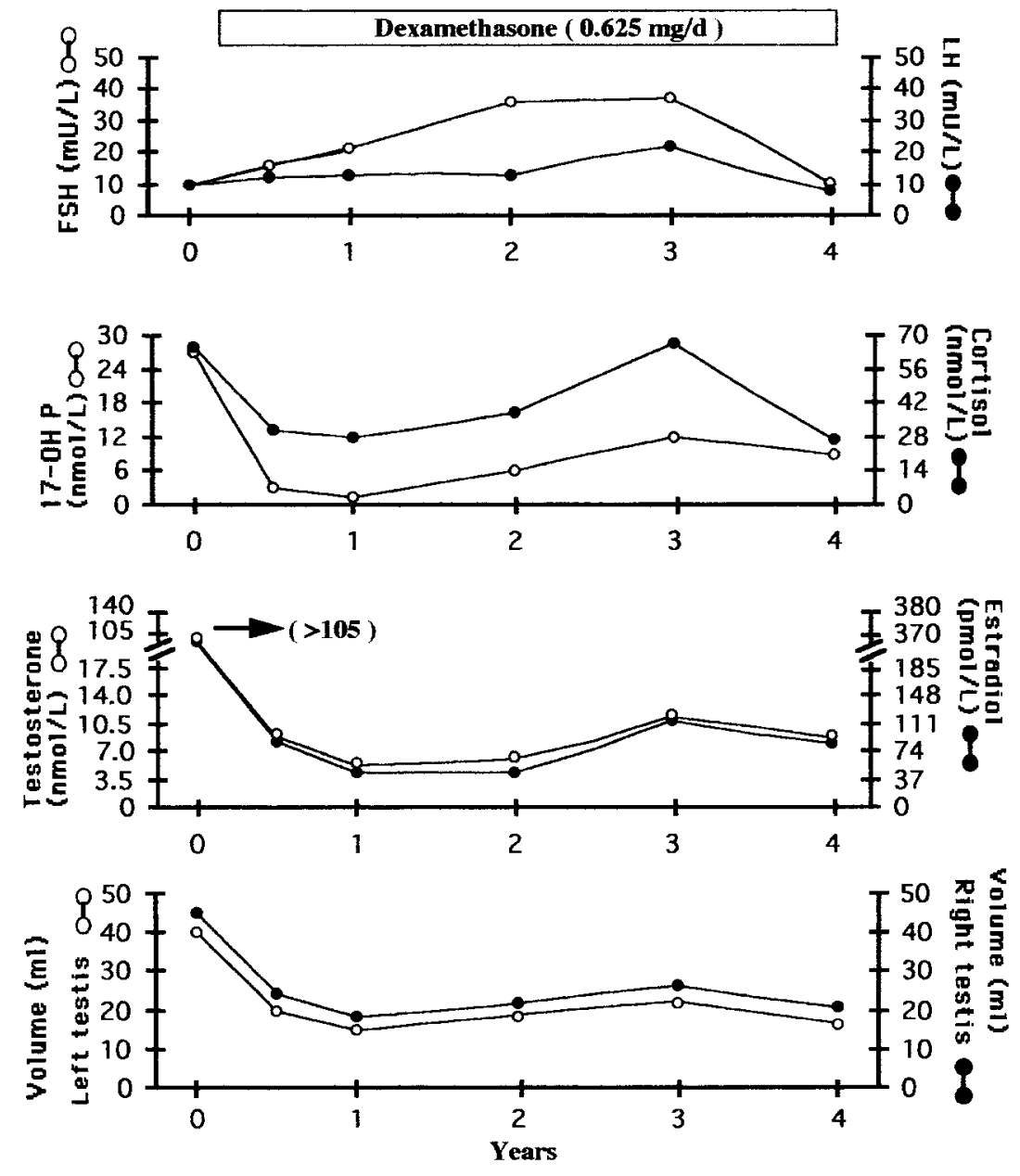

CAH (21-OHase deficiency) in homozygous non saltlosing form was made. Testicular nodules were interpreted as hyperplastic adrenal intra-testicular nodules (TAR).

In accordance with our diagnosis, two subsequent adrenal suppression tests normalized the abnormal serum levels of 17- $\mathrm{OH} \mathrm{P}$, testosterone and $\mathrm{E}_{2}$ (Table 1). The patient has been treated with oral dexamethasone (0.625 mg per day (d)) continuously, and returned to be followed-up for 4 years. The hormone abnormalities and macro-orchidism reverted quickly (see Results). Three nodules in the left testis and 4 nodules in the right testis were evident during the first year through the 4 th year of follow-up.

In 1996, at the age of 23 years, the patient came to the observation of SB. The testicular volumes were reduced (right testis $13 \mathrm{ml}$, left testis $10 \mathrm{ml}$ ) and only one nodule in the right testis was palpated. Ultrasonography showed that the left testis $(2.6 \times 1.5 \mathrm{~cm}) \mathrm{had}$ a normal structure and one epididymal cyst of $0.8 \mathrm{~cm}$ in diameter, while the right testis $(3.5 \times 1.4 \mathrm{~cm})$ had a dyshomogeneous structure with a single nodular area. Permission to perform a biopsy on this nodule was denied by the parents. Azoospermia was confirmed by semen analysis. Serum follicle-stimulating hormone (FSH) and $\mathrm{LH}$ were $22.8 \mathrm{mU} / \mathrm{l}$ and $6.8 \mathrm{mU} / \mathrm{l}$ respectively (normal values (n. v.) $1.0-11$ and 0.7-8.0 mU/l), $\mathrm{E}_{2}$ was $47.7 \mathrm{pmol} / \mathrm{l}$ (n.v. $<91.7 \mathrm{pmol} / \mathrm{l}$, males), testosterone was $13.5 \mathrm{nmol} / \mathrm{l}$ (n.v. 8.4$63.5 \mathrm{nmol} / \mathrm{l}$ ), $17-\mathrm{OH} \mathrm{P}$ was $2.7 \mathrm{nmol} / \mathrm{l}$ (n.v. 1.5$6.9 \mathrm{nmol} / \mathrm{l})$. We convinced both parents and his sister (an oligo-amenorrheic and moderately hirsute girl) to have an i. v. ACTH stimulation test (Synacthen, $250 \mu \mathrm{g}$ ) performed, but they declined to be sampled for DNA analysis. As suspected, the sister was heterozygous (basal and ACTH-stimulated 17-OH $\mathrm{P}=16.9$ and $35.4 \mathrm{nmol} / \mathrm{l})$ as were the mother $(18.1$ and $36.9 \mathrm{nmol} / \mathrm{l})$ and the father $(3.0$ and $34.8 \mathrm{nmol} / \mathrm{l})$. (Retrospectively, the death of the brother (see above) was interpreted as due to the salt-losing form of 21-OHase deficiency.) Except for one ACTH stimulation test and two hCG stimulation tests (see Results), no other study was conducted, as the patient was lost again to follow-up. 


\section{Results}

\section{Initial evaluation and first 4 years of follow-up}

The pertinent hormone data at first observation are summarized in Table 1 and the follow-up data in Fig. 1. In addition to the increased levels of 17-OH P (18- and 5-fold higher than the upper normal limit for prepuberal boys and adult males respectively) and testosterone ( $>300$ - and $>4$-fold higher), increased serum levels of $\mathrm{E}_{2}$ (10- and 4-fold higher) occurred. Six months following the beginning of the dexamethasone therapy, serum 17-OH-P, testosterone and $\mathrm{E}_{2}$ declined considerably, and this improvement persisted through the first year of follow-up (Fig. 1). This sharp reduction was accompanied by a progressive increase in serum gonadotropins. At the end of the first year and at the end of the second year, i.v. LH releasing hormone (LHRH) elicited appreciable responses of gonadotropins $(\Delta \mathrm{FSH}=3.3$ and $14 \mathrm{mU} / \mathrm{l}, \Delta \mathrm{LH}=3.5$ and $31 \mathrm{mU} / \mathrm{l})$ compared with the pre-therapy absence of response $(\Delta=0.2$ and $1.4 \mathrm{mU} / \mathrm{l}$ respectively). Serum gonadotropins peaked at the third year, but this rise was transient
(Fig. 1). Not shown in the figure is that serum ACTH and dehydroepiandrosterone sulfate (DHEAS) remained low during these four years of follow-up $(<6.6 \mathrm{pmol} / \mathrm{l}$ and $<0.8 \mu \mathrm{mol} / \mathrm{l}$ respectively).

The surge in FSH and LH secretion was paralleled by a simultaneous increase in serum 17-OH P, testosterone and $\mathrm{E}_{2}$ (Fig. 1) and a 3-fold increase in serum cortisol (from 24.8 to $69 \mathrm{nmol} / \mathrm{l}$ ). At the 4 th year of follow-up, when serum gonadotropins declined, 17-OH P, testosterone and $\mathrm{E}_{2}$ declined in parallel as did cortisol $(69 \mathrm{nmol} / \mathrm{l}$ to $33.1 \mathrm{nmol} / \mathrm{l})$. This parallel fluctuation of gonadotropins and steroids suggested gonadotropin responsiveness of TAR. This responsiveness was substantiated by the parallel changes in testicular volume, the right testis remaining larger than the left one, as well as by the results of the hCG test. As indicated in the Case report, all nodules had disappeared except for four in the right gonad and three in the left one.

\section{hCG and ACTH stimulation tests}

While on dexamethasone therapy, the patient was subjected to four hCG tests (Fig. 2) - two in 1983 (first year of follow-up) and two in 1996 (13th year of
Year 1983
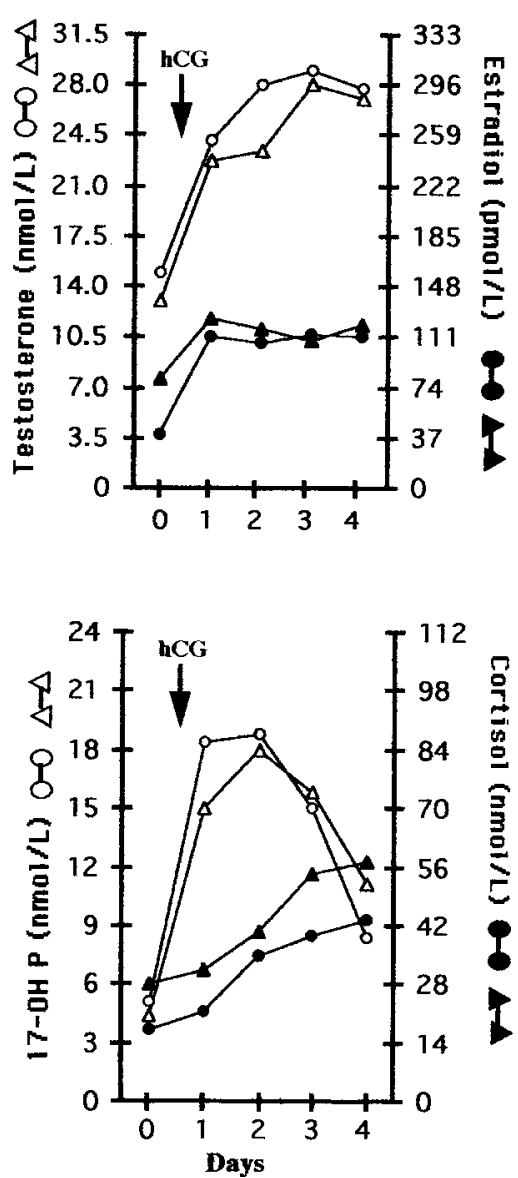

\section{Year 1996}
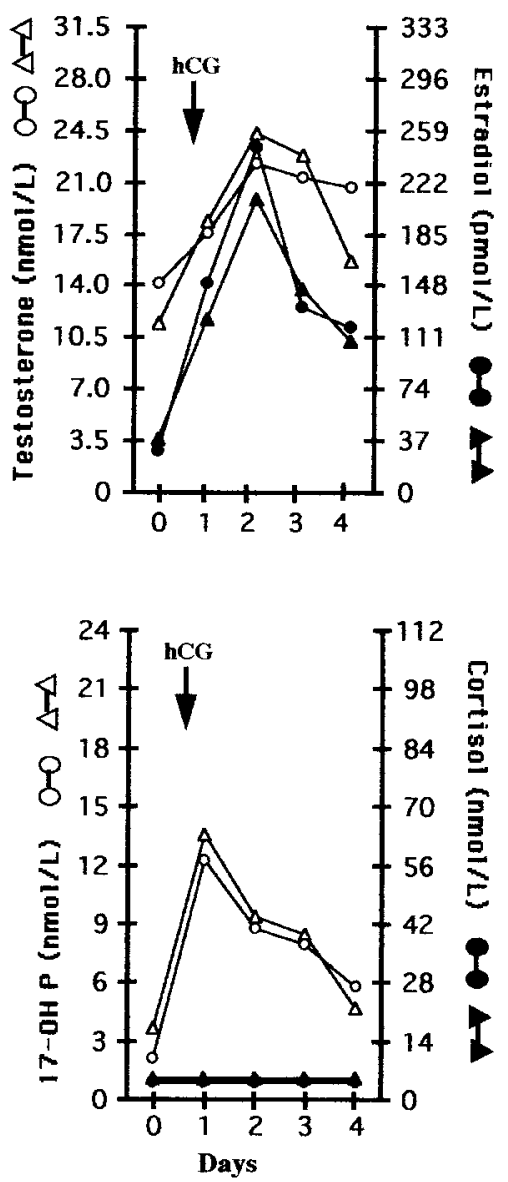

Figure 2 Human chorionic gonadotropin (hCG) stimulation test performed in 1983 (left panels) and 1996 (right panels). The two tests done in 1983 (when the patient was 10 years old) were performed 2 months apart, as were the two performed in 1996. (Not shown is that, in all four tests, DHEAS was suppressed $(<0.3 \mu \mathrm{mol} / \mathrm{l})$ both prior to and after the hCG stimulus.) The patient received continuous dexamethasone treatment. The hCG test was performed by injecting i.m. a single dose (5000 IU) of Profasi (Serono). In one of the two hCG tests performed in 1996, blood sampling commenced within the first two hours after hCG injection (see middle and bottom panels of Fig. 3). 
follow-up). At both examinations the patient complained of bilateral testicular discomfort and the nodules were painful to palpation. The reproducibility of each pair of tests was excellent, but the results of the most recent differed from the earlier ones. In the last two tests, testosterone increased 1.7- to 2.0-fold, $\mathrm{E}_{2}$ increased 6- to 8-fold and 17-OH P increased 3.5- to 5 -fold. In the first two tests, the corresponding increases had been 2-fold, 2-fold and 4-fold. Cortisol response was also different: it was reproducibly unstimulated $(<13.8 \mathrm{nmol} / \mathrm{l})$ in the two 1996 tests, while it had increased 2-fold, in a step-wise fashion, 13 years before. (Not shown in Fig. 2, and in Fig. 3 as well, is that DHEAS was always suppressed $(<0.3 \mu \mathrm{mol} / \mathrm{l})$ both prior to and after the stimuli.) On one occasion (1996), the hCG test was performed by sampling over the first six hours in order to compare the early response of steroids under the hCG stimulus with that under the ACTH stimulus (contrast broken with continuous lines in Fig. 3). The ACTH test performed in 1983 is shown in the top panel of Fig. 3, while the one performed in 1996 is shown in the middle and bottom panels of Fig. 3. In 1983, a prompt and small but definite response in cortisol and a greater, biphasic response of $17-\mathrm{OH} \mathrm{P}$ were noted. A totally different pattern was observed in 1996 when the patient had a single nodule in the right testis. Under the ACTH stimulus, no secretion of cortisol was seen, while secretion of $17-\mathrm{OH} \mathrm{P}$ was protracted. Under the ACTH stimulus (Fig. 3, middle and bottom panels) testosterone, $\mathrm{E}_{2}$ and 17-OH $\mathrm{P}$ increased 1.3-fold (peak at $30 \mathrm{~min}$ and subsequent plateau), 1.4-fold (peak at $30 \mathrm{~min}$ and subsequent plateau) and 7-fold (peak at $90 \mathrm{~min})$ respectively. With the hCG stimulus, the corresponding increases were 1.3-fold, 1.3-fold (peak at $30 \mathrm{~min}$ ), while $17-\mathrm{OH} \mathrm{P}$ and cortisol did not change. The prompt secretion of steroid hormones under the ACTH stimulus vs their largely retarded secretion under the hCG stimulus was observed both in 1983 and 1996, and indicated that the nodules present in those years more than likely contained distinct ACTH and LH/hCG receptors, since hybrid ACTH/hCG receptors would have transmitted either stimulus in the same manner.
Figure 3 Steroid hormone response to i.v. synthetic ACTH (Synacthen, $250 \mu \mathrm{g}$; continuous line) or i.m. hCG (discontinuous line). Top pane pertains to the year 1983, middle and bottom panels to the year 1996 . No early sampling was performed after the hCG test performed in 1983. For the continuation of the hCG test performed in 1996 (i.e. 24, 48, 72 and $96 \mathrm{~h}$ time points), see right panels in Fig. 2. Both in 1983 and in 1996 the ACTH test was separated from the hCG test by a two-month interval. Not shown is that DHEAS was $<0.3 \mu \mathrm{mol} / \mathrm{l}$ at all time points in the two ACTH tests.
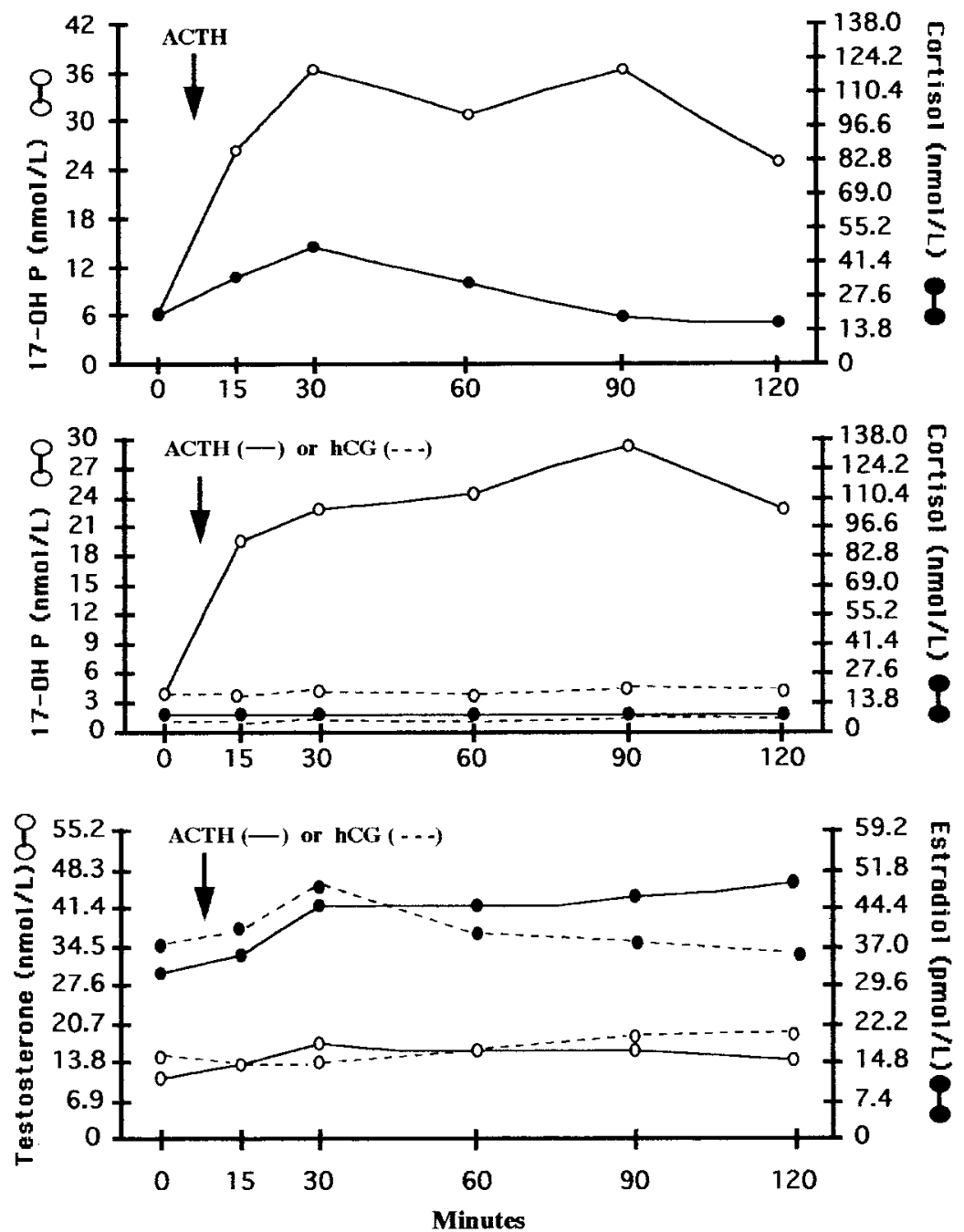
When the recent hCG test results are compared with the earlier hCG results (Fig. 2), it appears that TAR responsiveness to $\mathrm{LH} / \mathrm{hCG}$ changed quantitatively and qualitatively: (i) the capability to secrete cortisol was lost; (ii) the capability to secrete 17-OH-P (whose peak of secretion was anticipated by $24 \mathrm{~h}$ ) and testosterone was reduced; (iii) the capability to secrete $\mathrm{E}_{2}$ (whose peak of secretion was postponed by $24 \mathrm{~h}$ ) increased remarkably.

\section{Discussion}

Kirkland et al. (7) speculated that LH may play a role in the growth of TAR. More recently, Combes-Moukhovsky et al. (1) showed that a single hCG test (5000 IU) under dexamethasone treatment caused a significant, although very transient, increase in both cortisol and 17-OH-P, but no significant increase in $\mathrm{E}_{2}$ and testosterone. Rather than appreciating the positive response, '. .. as hCG/LH receptors have never been described for adrenal tissue' (1), these authors gave more attention to the negative response and concluded that '... all of the testicular tissue was inactive or destroyed'. It is of interest that their patient had supranormal levels of $E_{2}(1)$, although not as high as our patient. Clark et al. (5) measured LH receptors in membrane-rich fractions of TAR using a binding assay and commercially available '... partially purified hCG'; no binding was demonstrated. The following evidence supports the existence of $\mathrm{LH} / \mathrm{hCG}$ receptors in TAR of our patient: (i) parallel changes of serum LH and steroid hormones at the time of the 'biochemical puberty', when ACTH was constantly low; (ii) consistent hCG stimulation of steroidogenesis, although not all steroids were responsive at the last hCG stimulation test that was performed; (iii) transient increase in the volume of the nodules at the time of the transient increase in serum LH.

A phenomenon described for TAR is autonomization (or adenomatous transformation), which may take several forms. Usually it refers to lack of regression or to recurrence after excision, even though steroidogenesis had been suppressed. Impressive cases of TAR autonomization from ACTH are the one reported by Blumberg-Tick et al. (8) and especially the one reported by Clark et al. (5). At 19 years of age, TAR responded to corticosteroids within one week, but 4 years later - with serum FSH at $21 \mathrm{mU} / \mathrm{l}$ and $\mathrm{LH}$ at $11 \mathrm{mU} / \mathrm{l}$ - TAR were unresponsive to $4 \mathrm{mg}$ /day dexamethasone, even though serum 17-OH P was suppressed (5). Thus, surgical excision of several nodules was performed. In spite of the combined corticosteroid plus testosterone enanthate therapy, nodules recurred (5). In the afore-mentioned case of Combes-Moukhovsky et al. (1), the suppression of steroid hormone levels in the peripheral and adrenal vein, but not in the gonadal vein, was interpreted "suggesting the early occurrence of autonomous hormonal secretion of the testicular masses'.

The bilateral nature of TAR - which parallels the bilateral nature of the associated adrenal gland hyperplasia - should argue against the precocity of the autonomization, although unilateral TAR have been reported (9). On the other hand, the right testis of our patient was always larger than the left testis. After one year of ACTH-suppressive therapy, three nodules were evident in the left testis but four in the right testis; at the last follow up, only one nodule existed in the right testis. We believe that this nodule was present since the first visit and accounted for the consistent difference in size between the right and the left gonad. In addition, comparison of the top with the middle panel in Fig. 3 shows that the $17-\mathrm{OH} \mathrm{P}$ profile changed. The $17-0 \mathrm{H} \mathrm{P}$ profile was clearly biphasic (top panel). The first peak, coinciding with the cortisol peak, occurred at $30 \mathrm{~min}$; the second peak occurred at $90 \mathrm{~min}$, matching the 90-min peak given by the ACTH stimulation of the single nodule (middle panel). No additional cortisol peak was possible at $90 \mathrm{~min}$ (top panel) because this nodule failed to produce cortisol.

An additional important observation is that secretions, at any age, of any given steroid under the ACTH stimulation vs the hCG stimulation had consistently different kinetics. These differences militate against the possible existence, in TAR, of ACTH/LH hybrid receptors. In fact, if present, such hybrid receptors would have transduced either signal (ACTH or LH/hCG) in the same manner. Therefore, ACTH and LH/hCG receptors of TAR are distinct entities.

We believe that our patient already had at least three distinct populations of TAR when 10 years old. The first and prevalent population consisted of the nodules whose mass and secretion were suppressed early after dexamethasone therapy; these nodules were therefore fully ACTH-responsive, both in terms of growth and steroidogenesis. The second population consisted of three nodules in each gonad that were (i) partially responsive to (or partially autonomous from) ACTH, since suppression of growth lagged behind the prompt suppression of steroidogenesis, and (ii) responsive to $\mathrm{LH} / \mathrm{hCG}$, since size and steroidogenesis fluctuated in parallel with LH/hCG. The third population consisted of a single nodule in the right testis. The growth of this nodule was unresponsive to ACTH (since, unlike all other nodules, it did not disappear after several years of uninterrupted dexamethasone therapy) and was also unresponsive to gonadotropins (since it did not grow further in the face of serum levels of LH persistently in the high-normal range). The steroidogenesis of this nodule was partially responsive to both ACTH and LH/hCG. Unlike the second population of TAR, this nodule lost the property to synthesize cortisol. This fact should explain why serum cortisol was always measurable in 1983 to 1987 , when the patient had the second and third population of TAR, but was undetectable in 1996, when only the third population survived.

As mentioned in the Introduction, pluripotent ACTHsensitive stromal cells of the testes can differentiate into 
adrenal-like or Leydig-like cells depending upon the appropriate stimulus. Due to the early, prenatal and chronic exposure to endogenous ACTH vs the late, postnatal and acute exposure to the six injections of hCG, the differentiation along the 'adrenal-like' direction (i.e. our first group of TAR) predominated largely over the differentiation in the 'Leydig-like' direction (i.e. our second and third group of TAR). However, all staminal cells had undergone differentiation because no additional TAR appeared over the 13 years of follow-up.

Considering the very high levels of circulating sex hormones, serum gonadotropins surprisingly were unsuppressed, possibly because of a concurrent event which tended to raise their concentration (i.e. testicular damage by the cryptorchid state). Endogenous gonadotropins could have contributed, with hCG injections, to the Leydig-like differentiation (i.e. second and third group of TAR) and ultimately may have given a selective advantage to the third group of TAR.

\section{Acknowledgements}

Dr F Lo Giudice was supported by a 'Dottorato di Ricerca in Biologia Cellulare Umana' from the Faculty of Medicine of the University of Messina.

\section{References}

1 Combes-Moukhovsky ME, Kottler ML, Valensi P, Boudou P, Sibony M \& Attali JR. Gonadal and adrenal catheterization during adrenal suppression and gonadal stimulation in a patient with bilateral testicular tumors and congenital adrenal hyperplasia. Journal of Clinical Endocrinology and Metabolism 199479 13901394.

2 Johnson RE \& Scheithauer B. Massive hyperplasia of testicular adrenal rests in a patient with Nelson's syndrome. American Journal of Clinical Pathology 198177 501-507.

3 Hamwi GJ, Gwinup G, Mostow JH \& Besch PK. Activation of testicular adrenal rest tissue by prolonged excessive ACTH production. Journal of Clinical Endocrinology and Metabolism $196323861-869$.

4 Isidori A \& Di Luigi L. Tumori del testicolo. In Endocrinologia e Metabolismo, pp 822-826. Eds A Pinchera, G Faglia, G Giordano \& L Martini. Ambrosiana, Milano: Fisiopatologia e Clinica, 1991.

5 Clark RV, Albertson BD, Munabi A, Cassorla F, Aguilera G, Warren DW et al. Steroidogenic enzyme activities: morphology and receptor studies of a testicular adrenal rest in a patient with congenital adrenal hyperplasia. Journal of Clinical Endocrinology and Metabolism 199070 1408-1413.

6 Lanes R. Ambiguous genitalia, micropenis and cryptorchidism. In Pediatric Endocrinology, pp 237-266. Ed F Lifshitz. New York: Marcel Dekker, 1985.

7 Kirkland RT, Kirkland JL, Keenan BS, Bongiovanni AM, Rosenberg HS \& Clayton GW. Bilateral testicular tumors in congenital adrenal hyperplasia. Journal of Clinical Endocrinology and Metabolism 1977 44 369-378.

8 Blumberg-Tick J, Boudou P, Nahoul K \& Schiason G. Testicular tumors in congenital adrenal hyperplasia: steroid measurements from adrenal and spermatic veins. Journal of Clinical Endocrinology and Metabolism 199173 1129-1133.

9 Chrousos GP, Loriaux DL, Sherins RJ \& Cutler BG Jr. Unilateral testicular enlargement resulting from inapparent 21-hydroxylase deficiency. Journal of Urology 1981126 127-128.

Received 30 July 1998

Accepted 11 May 1999 